\title{
Risk of colorectal cancer and other cancers in patients with gall stones
}

\author{
C Johansen, Wong-Ho Chow, T Jørgensen, L Mellemkjaer, G Engholm, J H Olsen
}

\begin{abstract}
Background-The occurrence of gall stones has repeatedly been associated with an increased risk for cancer of the colon, but risk associated with cholecystectomy remains unclear.

Aims-To evaluate the hypothesis in a nationwide cohort of more than $\mathbf{4 0} \mathbf{0 0 0}$ gall stone patients with complete follow up including information of cholecystectomy and obesity.

Patients-In the population based study described here, 42098 patients with gall stones in 1977-1989 were identified in the Danish Hospital Discharge Register.

Methods-These patients were linked to the Danish Cancer Registry to assess their risks for colorectal and other cancers during follow up to the end of 1992 .

Results-The analysis showed a modest increase in the number of cancers at all sites combined ( $n=3940 ; \mathbf{R R}, 1.07 ; 95 \%$ confidence intervals $(\mathrm{CI}), 1 \cdot 0$ to $1 \cdot 1)$. A weak association was found for cancer of the colon (n=360; RR, 1.09; 95\% CI 1.0 to $1 \cdot 2)$, which remained unchanged when analysed by sex, anatomical subsite, and duration of follow up. Multivariate analysis with adjustment for cholecystectomy and clinically defined obesity did not change these estimates to any significant extent. Excess risks were found for cancers of the pancreas and the small intestine. $A$ non-significant increased risk for breast cancer was seen in women five years after initial discharge for gall stones.

Conclusion-A borderline significant association was seen between gall stones and cancer of the colon, and for cancer of pancreas and small intestine as well as for breast cancer in women.
\end{abstract}

Danish Cancer
Society, Division for Cancer Epidemiology, Copenhagen, Denmark C Johansen L Mellemkjaer G Engholm

J H Olsen

Epidemiology and Biostatistics Program, Division of Cancer Etiology, National Cancer Institute, Bethesda, Maryland, USA

Wong-Ho Chow

Surgical Department K, Bispebjerg Hospital, University of Copenhagen, Copenhagen, Denmark $T$ Jørgensen

Correspondence to: Dr C Johansen, Danish Cancer Society, Division for Cancer

Epidemiology, DK-2100 Copenhagen $\emptyset$, Denmark.

Accepted for publication 18 April 1996

(Gut 1996; 39: 439-443)

Keywords: gall stones, cholecystectomy, obesity, colorectal cancer.

Reports of high faecal excretion of bile acids and bile derivatives by patients with colorectal cancer and those with cholecystectomy ${ }^{12}$ have intensified research into the relation between gall stones and colorectal cancer. Several studies of gall stone patients have been reported $^{3-12}$; most showed a positive association with cancer of the colon, with relative risks of $1 \cdot 2-2 \cdot 4$. In the studies that showed an effect and provided data on risk by anatomical subsite, the risk was generally greater for cancer of the proximal colon than for other parts of the colon and rectum..$^{8-12}$
Although the relation between cholecystectomy and colorectal cancer has been considered in many studies, the results are equivocal ${ }^{13}$; most of the case-control studies showed a positive relation, but only the two largest cohort studies showed significantly increased risks, which were restricted to women and to the proximal part of the colon. ${ }^{14} 15$

These results suggest that gall stones, and possibly cholecystectomy, which are done mainly as a result of gall stones increase the risk for colon cancer, particularly among women and in the proximal part of the colon. One hypothesis is that post-cholecystectomy changes in the composition and secretion of bile salts affect enterohepatic circulation and exposure of the colon to bile acids, ${ }^{16}{ }^{17}$ which may promote the development of colon cancer. ${ }^{18}$ On the other hand, abnormal bile acid and cholesterol metabolism that predisposes to gall stones also may increase the risk of colon cancer. ${ }^{19}$ The relation may also be influenced by shared determinants of gall stones and colon cancer such as oestrogens and obesity. ${ }^{2021}$

This study has the advantage in that it reports colon cancer as well as all other types of cancer among more than 40000 gall stone patients both with and without cholecystectomy in a large population based design. The analyses included information on a diagnosis of obesity.

\section{Methods}

The study population consisted of patients who had been discharged from hospital with a diagnosis of gall stones in 1977-1989. In 1977, the Danish National Board of Health established a population based Hospital Discharge Register, which keeps records of more than $99 \%$ of all hospital discharges for somatic diseases. ${ }^{22}$ The information on each discharged patient includes the personal identification number, which is a unique 10 digit number for every Danish citizen, date of discharge, and up to 20 diagnoses per discharge, classified according to a Danish modification of the International Classification of Diseases, eighth revision (ICD-8).$^{23}$ In addition, surgical procedures are recorded and classified according to the Danish Classification of Surgical Procedures and Therapies. ${ }^{23}$

All discharge records for 1977-1989 that included a diagnosis of cholecystolithiasis (ICD-8: 574.00) or cholelithiasis (574.09) were abstracted. For patients who had been discharged more than once with such a diagnosis, the day of the first hospital discharge 
was used as the date of entry into the cohort; it should be noted, however, that some patients may have had gall stones before 1977. The full discharge history of each patient was searched to obtain any information on a diagnosis of obesity and cholecystectomy. Using the personal identification number, linkage was made to the Danish National Board of Health to obtain information on vital status, and to the Danish Cancer Registry, which has been in operation since 1942, to obtain information on incident cancers. ${ }^{24}$ of 49070 patients initially identified in the Hospital Discharge Register, we excluded $3654(7 \cdot 4 \%)$ patients who had a cancer of the abdominal organs or breast before the initial hospital discharge for gall stones and $3318(6 \cdot 6 \%)$ who died during the first year of follow up, leaving 42098 patients for the study (Table I). Among them, $72 \%$ had cholecystectomy, and $95 \%$ of which were performed within a year of the index gall stone diagnosis.

Patients were followed up for cancer occurrence from one year after discharge for gall stones until the date of death or the end of 1992, whichever came first. The observed

TABLE I Descriptive characteristics of patients with a diagnosis of gall stones at hospital discharge, Denmark, 1977-89

\begin{tabular}{|c|c|c|c|}
\hline Characteristic & $\begin{array}{l}\operatorname{Men}(\%) \\
(n=10904)\end{array}$ & $\begin{array}{l}\text { Women (\%) } \\
(n=31 \text { 194) }\end{array}$ & $\begin{array}{l}\text { Both sexes (\%) } \\
(n=42098)\end{array}$ \\
\hline \multicolumn{4}{|l|}{ Period of diagnosis } \\
\hline $1977-80$ & $31 \cdot 3$ & $33 \cdot 3$ & $32 \cdot 8$ \\
\hline $1981-84$ & $30 \cdot 8$ & $30 \cdot 7$ & $30 \cdot 7$ \\
\hline $1985-89^{\star}$ & $37 \cdot 8$ & $36 \cdot 0$ & $36 \cdot 5$ \\
\hline \multicolumn{4}{|l|}{ Age at discharge $(y)$} \\
\hline$<30$ & $2 \cdot 3$ & $9 \cdot 8$ & $7 \cdot 8$ \\
\hline $30-39$ & $7 \cdot 2$ & $12 \cdot 5$ & $11 \cdot 1$ \\
\hline $40-49$ & $13 \cdot 2$ & $14 \cdot 1$ & 13.9 \\
\hline $50-59$ & $20 \cdot 0$ & $18 \cdot 2$ & $18 \cdot 7$ \\
\hline $60-69$ & $26 \cdot 7$ & $19 \cdot 9$ & $21 \cdot 6$ \\
\hline$\geq 70$ & $30 \cdot 6$ & $25 \cdot 6$ & $26 \cdot 9$ \\
\hline Cholelithiasis with cholecystectomy & $67 \cdot 5$ & $74 \cdot 1$ & $72 \cdot 4$ \\
\hline Cholelithiasis without cholecystectomy & $32 \cdot 5$ & 25.9 & $27 \cdot 6$ \\
\hline Record of obesity $\dagger$ & $3 \cdot 2$ & $5 \cdot 9$ & $5 \cdot 2$ \\
\hline
\end{tabular}

*Includes five years. $\nmid$ A diagnosis of obesity stated in any of the hospital discharge records of the patient.

TABLE II Observed and expected numbers of cancer* among 42098 patients with a diagnosis of gall stones on their discharge record, Denmark, 1977-89

\begin{tabular}{lcccl}
\hline Site & Observed & Expected & $R R \dagger$ & $95 \% C I$ \\
\hline All neoplasms & 3940 & 3670 & 1.07 & 1.0 to 1.1 \\
Buccal cavity and pharynx & 74 & 59.2 & 1.25 & 1.0 to 1.6 \\
Oesophagus & 41 & 30.6 & 1.34 & 1.0 to 1.8 \\
Stomach & 118 & 110.1 & 1.07 & 0.9 to 1.3 \\
Small intestine & 23 & 8.8 & 2.60 & 1.6 to 3.9 \\
Colon & 360 & 329.9 & 1.09 & 1.0 to 1.2 \\
Rectum & 156 & 162.3 & 0.96 & 0.8 to 1.1 \\
Liver & 56 & 33.0 & 1.70 & 1.3 to 2.2 \\
Pancreas & 145 & 109.1 & 1.33 & 1.1 to 1.6 \\
Larynx & 24 & 25.7 & 0.93 & 0.6 to 1.4 \\
Lung & 409 & 400.0 & 1.02 & 0.9 to 1.1 \\
Breast & 521 & 496.3 & 1.05 & 1.0 to 1.1 \\
Cervix uteri & 68 & 81.1 & 0.84 & 0.7 to 1.1 \\
Corpus uteri & 131 & 118.8 & 1.10 & 0.9 to 1.3 \\
Ovary & 94 & 103.3 & 0.91 & 0.7 to 1.1 \\
Prostate & 169 & 166.2 & 1.02 & 0.9 to 1.2 \\
Testis & 3 & 4.4 & 0.68 & 0.1 to 2.0 \\
Kidney & 113 & 93.7 & 1.21 & 1.0 to 1.5 \\
Urinary bladder & 189 & 184.9 & 1.02 & 0.9 to 1.2 \\
Melanoma & 57 & 75.2 & 0.76 & 0.6 to 1.0 \\
Non-melanoma skin & 553 & 534.0 & 1.04 & 1.0 to 1.1 \\
Brain & 87 & 74.3 & 1.17 & 0.9 to 1.4 \\
Non-Hodgkin's lymphoma & 85 & 74.0 & 1.15 & 0.9 to 1.4 \\
Hodgkin's lymphoma & 9 & 8.4 & 1.07 & 0.5 to 2.0 \\
Multiple myeloma & 42 & 36.0 & 1.17 & 0.8 to 1.6 \\
Leukaemia & 103 & 76.3 & 1.35 & 1.1 to 1.6 \\
Other specified & 132 & 109.2 & 1.21 & 1.0 to 1.4 \\
Secondary and unspecified & 115 & 104.4 & 1.10 & 0.9 to 1.3 \\
\hline
\end{tabular}

$\mathrm{RR}$, Observed/Expected=ratio of observed to expected cancers; CI, confidence intervals. ${ }^{\star}$ First year of follow up excluded from the analysis. †Analysis adjusted for age, sex, and calendar year. numbers of cancers were compared with those expected on the basis of national incidence rates, which are divided into groups according to sex, age, and calendar time in five year intervals.

Multiplication of the person years under observation by the incidence rate yields the number of cancers that would be expected if patients with gall stones experienced the same risk as that prevailing in the general population of Denmark. Tests of significance and 95\% confidence intervals (CI) for the relative risk that is, the ratio of observed to expected cancers, were computed on the assumption that the observed number of cancer cases in a specific category follows a Poisson distribution, using Byar's approximation. ${ }^{25}$ Risks were estimated separately for patients with and without a cholecystectomy, as well as for the entire cohort combined. In addition, the effect of cholecystectomy, obesity, sex, age at diagnosis of gall stones and latency since first discharge with a gall stone diagnosis were adjusted for in multiplicative Poisson regression models that incorporated the national rates as the standard, ${ }^{26}$ using the Epicure statistical package. ${ }^{27}$ As the risks were not affected substantially by adjustment for these factors, only results adjusted for age, sex, and calendar years will be presented in the Tables.

\section{Results}

The $\mathbf{4 2} 098$ gall stone patients included in the study accrued 312784 person years of follow up, with an average of 7.4 years each (range, 1-16 years). The median age at the entry in the cohort was 63 years for men and 57 years for women. The male to female ratio was $0 \cdot 4$. A diagnosis of obesity was noted in 2190 (5.2\%) patients (Table I).

Overall, 3940 cancers were observed compared with 3670 expected, yielding a small but significantly increased relative risk of 1.07 (Table II), 1.07 in men and 1.08 in women. The increase was due mainly to slight but statistically significant increases in the risk for non-melanoma skin cancer $(R R, 1.04)$, cancers of the breast $(1.05)$, colon $(1.09 ; 1.17$ in men and 1.06 in women), kidney $(1.21)$, buccal cavity and pharynx (1.25), pancreas (1.33), and oesophagus (1.34), and of leukaemia (1.35). Greater increases in the risk were found for cancer of the liver $(1 \cdot 70)$ and small intestine $(2 \cdot 60 ; 2 \cdot 18$ in men and $2 \cdot 84$ in women). However, with duration of follow up risks remained significantly increased only for cancers of the breast, pancreas, leukemia, and small intestine (Table III). No excess was observed for cancer of the rectum in either of the sexes (RR in both sexes combined, 0.96).

Table III also gives the relative risks for cancers of selected sites of the gastrointestinal tract by conduct of cholecystectomy. There seemed to be no systematic effect of treatment modality on the relative risks for the individual cancer sites, colon included. An analysis of the 23 histologically confirmed tumours of the small intestine showed that the excess risk was mainly confined to carcinoid tumours $(n=15$; 
TABLE III Relative risk * for cancers of the liver, pancreas, the lower gastrointestinal tract, female breast, and leukaemia among 42098 patients with gall stones by type of treatment and time since known hospital discharge reporting the disease, Denmark, 1977-89

\begin{tabular}{|c|c|c|c|c|c|c|c|c|c|}
\hline \multirow{3}{*}{$\begin{array}{l}\text { Site } \\
\text { Cholecystectomy } \\
\text { (yes; no; combined group) }\end{array}$} & \multirow[b]{3}{*}{ Number } & \multirow[b]{3}{*}{$R R$} & \multirow[b]{3}{*}{$95 \% C I$} & \multicolumn{6}{|c|}{ Time since first known discharge (years) $\dagger$} \\
\hline & & & & \multicolumn{3}{|c|}{ Early follow up (1-4) } & \multicolumn{3}{|c|}{ Late follow up (5-16) } \\
\hline & & & & Number & $R R$ & $95 \% C I$ & Number & $R R$ & $95 \% C I$ \\
\hline \multicolumn{10}{|l|}{ Pancreas } \\
\hline yes & 105 & $1 \cdot 42$ & $1 \cdot 2$ to 1.7 & 49 & 1.51 & $1 \cdot 1$ to $2 \cdot 0$ & 56 & 1.35 & 1.0 to 1.8 \\
\hline no & 40 & $1 \cdot 14$ & 0.8 to 1.6 & 27 & $1 \cdot 33$ & 0.9 to 1.9 & 13 & 0.88 & 0.5 to 1.5 \\
\hline combined group & 145 & 1.33 & $1 \cdot 1$ to 1.6 & 76 & & $1 \cdot 1$ to 1.8 & 69 & 1.22 & 1.0 to 1.5 \\
\hline \multicolumn{10}{|l|}{ Small intestine } \\
\hline yes & 16 & $2 \cdot 63$ & 1.5 to 4.3 & 10 & $3 \cdot 70$ & 1.8 to 6.8 & 6 & $1 \cdot 78$ & 0.6 to 3.9 \\
\hline no & 7 & $2 \cdot 54$ & 1.0 to $5 \cdot 2$ & 3 & 1.89 & 0.4 to 5.5 & 4 & 3.43 & 0.9 to 8.8 \\
\hline combined group & 23 & $2 \cdot 60$ & 1.6 to 3.9 & 13 & 3.03 & 1.6 to $5 \cdot 2$ & 10 & $2 \cdot 20$ & $1 \cdot 1$ to 4.0 \\
\hline \multicolumn{10}{|l|}{ Colon $\ddagger$} \\
\hline yes & 225 & 1.09 & $1 \cdot 0$ to $1 \cdot 2$ & 97 & $1 \cdot 13$ & 0.9 to 1.4 & 128 & 1.06 & 0.9 to 1.3 \\
\hline no & 111 & $1 \cdot 10$ & 0.9 to 1.3 & 58 & 1.03 & 0.8 to 1.3 & 53 & $1 \cdot 20$ & 0.9 to 1.6 \\
\hline combined group & 336 & 1.09 & $1 \cdot 0$ to 1.2 & 155 & 1.09 & 0.9 to 1.3 & 181 & $1 \cdot 10$ & 0.9 to 1.3 \\
\hline \multicolumn{10}{|l|}{ Rectum $\neq$} \\
\hline yes & 119 & 1.07 & 0.9 to 1.3 & 52 & $1 \cdot 07$ & 0.8 to 1.4 & 67 & 1.07 & 0.8 to 1.4 \\
\hline no & 36 & 0.69 & 0.5 to 1.0 & 24 & 0.80 & 0.5 to 1.2 & 12 & 0.54 & 0.3 to 0.9 \\
\hline combined group & 155 & 0.95 & $0 \cdot 8$ to $1 \cdot 1$ & 76 & 0.97 & $0 \cdot 8$ to $1 \cdot 2$ & 79 & 0.93 & $0 \cdot 7$ to $1 \cdot 2$ \\
\hline \multicolumn{10}{|l|}{ Breast } \\
\hline combined group & 518 & $1 \cdot 05$ & $1 \cdot 0$ to $1 \cdot 1$ & 202 & $0 \cdot 90$ & 0.9 to 1.0 & 316 & $1 \cdot 17$ & $1 \cdot 0$ to $1 \cdot 3$ \\
\hline combined group & 103 & 1.35 & $1 \cdot 1$ to 1.6 & 48 & $1 \cdot 30$ & 1.0 to 1.7 & 55 & $1 \cdot 40$ & 1.1 to 1.8 \\
\hline
\end{tabular}

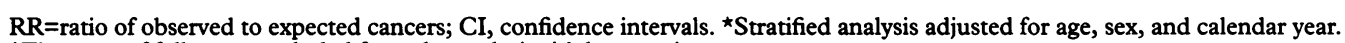
†First year of follow up excluded from the analysis. ‡Adenocarcinoma.

TABLE IV Relative risk for cancer of colon (adenocarcinoma) among 42098 patients with gall stones by subsite of cancer and time since first known hospital discharge reporting the disease, Denmark, 1977-89

\begin{tabular}{|c|c|c|c|c|c|c|c|c|c|}
\hline \multirow[t]{3}{*}{ Subsite } & \multirow[b]{3}{*}{ Number } & \multirow[b]{3}{*}{$R R$} & \multirow[b]{3}{*}{$95 \% C I$} & \multicolumn{6}{|c|}{ Time since first known discharge (years) $\dagger$} \\
\hline & & & & \multicolumn{3}{|c|}{ Early follow up (1-4) } & \multicolumn{3}{|c|}{ Late follow up (5-16) } \\
\hline & & & & Number & $R R$ & $95 \% C I$ & Number & $R R$ & $95 \% C I$ \\
\hline $\begin{array}{l}\text { Right colon } \ddagger \\
\text { Mid-colon } \ddagger \\
\text { Left colon } \ddagger\end{array}$ & $\begin{array}{r}124 \\
49 \\
163\end{array}$ & $\begin{array}{l}1 \cdot 19 \\
1.09 \\
1.03\end{array}$ & $\begin{array}{l}1.0 \text { to } 1.4 \\
0.8 \text { to } 1.4 \\
0.9 \text { to } 1.2\end{array}$ & $\begin{array}{l}56 \\
21 \\
78\end{array}$ & $\begin{array}{l}1.17 \\
0.99 \\
1.07\end{array}$ & $\begin{array}{l}0.9 \text { to } 1.5 \\
0.6 \text { to } 1.5 \\
0.8 \text { to } 1.3\end{array}$ & $\begin{array}{l}68 \\
28 \\
85\end{array}$ & $\begin{array}{l}1 \cdot 21 \\
1 \cdot 18 \\
1.00\end{array}$ & $\begin{array}{l}0.9 \text { to } 1.5 \\
0.8 \text { to } 1.7 \\
0.8 \text { to } 1.2\end{array}$ \\
\hline
\end{tabular}

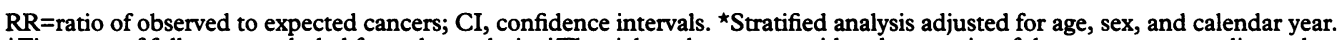
†First year of follow up excluded from the analysis. ¥The right colon was considered to consist of the caecum, appendix, and ascending colon, the mid-colon of the transverse colon and the hepatic and splenic flexures, and the left colon of the descending colon, the sigmoid flexure, the sigmoid colon, and the rectosigmoid colon.

$\mathrm{RR}, 4.05 ; 95 \% \mathrm{CI}, 2 \cdot 3$ to $6 \cdot 7$ ), whereas the excess risk for other subgroups, mainly adenocarcinomas, was non-significant $(n=8$; $\mathrm{RR}, 1.50 ; 95 \% \mathrm{CI}, 0.6$ to 3.0 ) (data not shown in Table). A similar analysis by histological subgroup of 96 cases of leukaemia showed excess risk for chronic myeloid leukaemia ( $\mathrm{n}=$ 18 ; RR, $1.75 ; 95 \% \mathrm{CI}, 1.0$ to 2.8 ), acute myeloid leukaemia ( $n=37 ; R R, 1.35 ; 95 \% C I$, 1.0 to 1.9 ) and a non-significant increased risk of chronic lymphatic leukaemia $(n=41 ; R R$, $1.09 ; 95 \%$ CI, $0 \cdot 8$ to $1 \cdot 5)$.

Stratification of risk analyses by anatomic subsite of colon showed a tendency, although still non-significant, for highest increase in the right colon, with a relative risk of 1.21 among

TABLE V Relative risk for cancer of the breast among 31194 female patients and relative risk for cancer of the colon * among 42098 patients by time since first known hospital discharge reporting gall stone disease excluding the first year of follow up, Denmark 1977-89

\begin{tabular}{|c|c|c|c|c|c|c|}
\hline \multirow{2}{*}{$\begin{array}{l}\text { Follow up } \\
\text { period }(y)\end{array}$} & \multicolumn{3}{|l|}{ Breast } & \multicolumn{3}{|l|}{ Colon } \\
\hline & Observed & $R R$ & $95 \%$ CI & Observed & $R R$ & $95 \% C I$ \\
\hline $\begin{array}{l}1-2 \\
3-4 \\
5-6 \\
7-8 \\
9-10 \\
11-12 \\
13+\end{array}$ & $\begin{array}{r}94 \\
108 \\
100 \\
84 \\
70 \\
39 \\
23\end{array}$ & $\begin{array}{l}0 \cdot 81 \\
1.00 \\
1 \cdot 12 \\
1 \cdot 18 \\
1.31 \\
1.09 \\
1 \cdot 14\end{array}$ & $\begin{array}{l}0.7 \text { to } 1.0 \\
0.8 \text { to } 1.2 \\
0.9 \text { to } 1.4 \\
0.9 \text { to } 1.5 \\
1.0 \text { to } 1.7 \\
0.8 \text { to } 1.5 \\
0.7 \text { to } 1.7\end{array}$ & $\begin{array}{l}76 \\
79 \\
65 \\
46 \\
35 \\
22 \\
13\end{array}$ & $\begin{array}{l}1.02 \\
1.16 \\
1.17 \\
1.05 \\
1.09 \\
1.04 \\
1.08\end{array}$ & $\begin{array}{l}0.8 \text { to } 1.3 \\
0.9 \text { to } 1.5 \\
0.9 \text { to } 1.5 \\
0.8 \text { to } 1.4 \\
0.8 \text { to } 1.5 \\
0.7 \text { to } 1.6 \\
0.6 \text { to } 1.8\end{array}$ \\
\hline
\end{tabular}

$\mathrm{RR}=$ ratio of observed to expected cancers; $\mathrm{CI}$, confidence intervals. ${ }^{\star}$ Adenocarcinoma of colon. patients with 5-16 years of follow up (1.43 among men and $1 \cdot 14$ among women) (Table IV). Multivariate analysis, with adjustment for cholecystectomy and clinically defined obesity, did not change these estimates to any significant extent (data not shown).

On the basis of more than 500 observed cases of breast cancer among gall stone patients, we found that the overall risk was increased by some $5 \%$. This modest but significant increase ranged from below unity at the start of the follow up (1-4 years) to some $17 \%$ above unity in the last period of follow up (5-16 years) (Table III). A closer follow up of patients showed that excess risk for breast cancer appeared five years after discharge for gall stones and remained non-significantly increased in the following years (Table V). The mutivariate analysis did not reveal separate effects of cholecystectomy and obesity and no significant trend was observed in the risk of breast cancer among women (data not shown). Table V also shows that the slightly increased risk for colon cancer remained almost unchanged in all follow up intervals.

\section{Discussion}

We report a modest, but significantly increased relative risk for cancers at all sites in a large nationwide cohort of $\mathbf{4 2} 098$ gall stone patients 
with 1-16 years of follow up. In previous studies, the occurrence of gall stones has been associated with an increased risk for colon cancer (3-12). In our study the modest 9\% increased risk for colon cancer remained unchanged when analysed by sex, latency and anatomical subsites of the colon. Although a causal relation between gall stones and colon cancer cannot be excluded on the basis of these results the weakness of the association more likely points to the effects of shared risk factors for these two diseases, such as metabolic factors, dietary factors or unknown factors. The absence of a convincing link between the occurrence of gall stones and colon cancer in our study might be explained by the high number of gall stone patients in the population who remains undiagnosed..$^{30}$ All patients with gall stones are included in the calculation of nationwide colon cancer rates, whereby they increase the expected number of cases, which, in turn, attenuate the observed relative risk of colon cancer.

Nearly all diagnoses of gall stones in Denmark included verification of stones by an $x$ ray or by ultrasound investigation, making misclassification due to overdiagnosis of the disease unlikely. The Danish Cancer Registry is nationwide and population based, and practically all cases of cancer occurring since 1943 have been notified, which highly reduces the possibilities for surveillance bias. To avoid any selective inclusion of patients with nonspecific symptoms of abdominal distress caused by a preclinical cancer of the colon or other abdominal organs and asymptomatic gall stones, we excluded the first year of follow up after the diagnosis of gall stones from the analysis of cancer.

Our finding was in line with those of a large follow up study from Sweden, which reported the overall risk for colon cancer close to unity in a population based cohort of 62615 patients (RR, $1.03 ; 95 \% \mathrm{CI}, 0.94$ to 1.14 ) who had undergone cholecystectomy, mainly for treatment of gall stones. ${ }^{15}$ The analysis by anatomic subsite in our study did not confirm the findings of the Swedish study, ${ }^{15}$ which reported a significantly increased risk for cancer of the right side of the colon in women that further increased with duration of follow up.

We observed a persistent increase in the risks for cancer of the pancreas and small intestine. To the best of our knowledge, neither cancer site has been associated with the occurrence of gall stones in earlier studies, ${ }^{1029}$ and a chance finding cannot be excluded.

Our finding of an increasing risk of breast cancer by duration of follow up is in line with one Swedish case control study of women with breast cancer, which showed a significantly positive association with gall stones. ${ }^{5}$ Another large cohort study with a maximum of 14 years of follow up showed no association on the basis of 202 observed breast cancers. ${ }^{30}$

Furthermore, no association between cholecystectomy and breast cancer was seen in the two case control studies of small sample size. ${ }^{3132}$ However, a smaller cohort study with a maximal follow up of 30 years showed a significantly increased risk on the basis of 27 cases. ${ }^{29}$ In our study the risk estimates for the first part of the follow up period may have been influenced by the exclusion of early, asymptomatic breast cancers during clinical preparation for gall stones.

The non-significant increased risk of breast cancer that appears five years after a diagnosis of gall stones in our study is probably not explained by heightened medical surveillance. Our results suggest that metabolic, hormonal or other determinants of gall stones may be risk factors for breast cancer.

In conclusion, we observed a borderline significant association between gall stones and cancer of the colon, which remained unchanged with duration of follow up. In addition the risk was not clearly confined to the proximal part of colon. We found that gall stone patients had an excess risk for gastrointestinal cancers, including the pancreas and small intestine and a non-significant risk of breast cancer was seen in women at least five years after a gall stone diagnosis. Cholecystectomy did not change these results.

1 Hill MJ, Drasar BS, Williams REO, et al. Faecal bile-acids and Clostridia in patients with cancer of the large bowel. Lancet 1975; i: 535-8.

2 Reddy BS, Wynder EL. Metabolic epidemiology of colon cancer. Cancer 1977; 39: 2533-9.

3 Doouss TW, Castleden WM. Gallstones and carcinoma of the large bowel. $N Z$ Med f 1973; 77: 162-5.

4 Turunen MJ, Kivilaakso EO. Increased risk of colorectal cancer after cholecystectomy. Ann Surg 1982; 194: 639-41.

5 Lowenfels AB, Domellöf L, Lindström CG, et al. Cholelithiasis, cholecystectomy and cancer: a case-control study in Sweden. Gastroenterology 1982; 83: 672-6.

6 von Schmauss, Ehrhardt U. Cholelitihasis - cholezystektomie und kolonkarzinom. Zentralbl Chir 1983; 108: 449-56.

7 Allende H, Ona FV, Davis HT. Gallbladder disease: risk factor for colorectal carcinoma? $\mathcal{F}$ Clin Gastroenterol 1984; 6: 51-5.

8 Machnik VG, Fuller C, Fuller J, et al. Explorative untersuchungen zum gemeinsamen vorkommen von cholelithiasis zustand nach cholezystectomie und kolonkarzinom. Dtsch Z Verdau-Stoffwechs 1986; 46: 22-9.

9 Gafá M, Sarli L, Sansebastiano G. Prevention of colorectal cancer. Dis Colon Rectum 1987; 30: 692-6.

10 Maringhini A, Moreau JA, Melton LJ, et al. Gallstones, gallbladder cancer, and other gastrointestinal malignancies. Ann Intern Med 1987; 107: 30-5.

11 Breuer NF, Katschinski B, Mörtl E, et al. Large bowel cancer risk in cholelithiasis and after cholecystectomy. Digestion 1988; 40: 219-26.

12 Jørgensen T, Rafaelsen S. Gallstones and colorectal cancer - there is a relationship, but it is hardly due to cholecystectomy. Dis Colon Rectum 1992; 35: 24-8.

13 Giovanucci E, Colditz GA, Stampfer MJ. A Meta-analysis of cholecystectomy and risk of colorectal cancer. Gastroenterology 1993; 105: 130-41.

14 Linos DA, Beard CM, O'Fallon WM, et al. Cholecystectomy and carcinoma of the colon. Lancet 1981; ii: 379-81.

15 Ekbom A, Yuen J, Adami H-O, et al. Cholecystectomy and colorectal cancer. Gastroenterology 1993; 105: 142-7.

16 Hepner GW, Hofmann AF, Malagelada JR, et al. Increased bacterial degradation of bile acids in cholecystectomized patients. Gastroenterology 1974; 66: 556-64.

17 Roda E, Aldini R, Mazzella G, et al. Enterohepatic circulation of bile acids after cholecystectomy. Gut 1978; 19: 640-9.

18 Bandettini L, Filiponi F, Romagnoli P. Increase of the mitotic index of colonic mucosa after cholecystectomy. Cancer 1986; 58: 685-7.

19 Almond HR, Reno Vlahcevic Z, Cooper Bell C, et al. Bile acid pools, kinetics and biliary lipid composition before and after cholecystectomy. $N$ Engl $f$ Med 1973; 289: 1213-6.

20 De Ward F, Baanders-van Halewiju EA. A prospective study in general practise on breast cancer risk in postin general practise on breast cancer risk in post

21 Layde PM, Vessey MP, Yeates D. Risk factors for gallbladder disease: a cohort study of young women attending bamily planning clinics. $₹$ Epidemiol Community Health family planning

22 Danish National Board of Health. The activity in the hospital care system. Copenhagen: Danish National Board of Health, 1981 [In Danish]. 
23 Danish National Board of Health. Classification of diseases (1976). Copenhagen: Danish National Board of Health, 1986. [In Danish].

24 Storm HH, Manders T, Friis S, et al Cancer incidence in Denmark 1990. Copenhagen: Danish Cancer Society, 1992.

25 Rothman KJ, Boice JD. Epidemiologic analysis with a programmable calculator (DHHS Publication 79-1649). Washington DC: US Government Printing Office, 1979

26 Breslow NE, Day NE. Statistical methods in cancer research Vol. II. The design and analysis of cohort studies. IARC Sci Pub No 82. Lyon: International Agency for Research on Cancer, 1987.

27 Preston DL, Lukin JH, Pierce DA, et al. Epicure. Seattle, USA: Hirosoft International Corporation, 1993.
28 Joergensen T. Gallstones. An epidemiological investigation (thesis). Dan Med Bulletin 1990; 37: 336-46.

29 Gudmundsson G, Möller TR, Olsson H. Cancer incidence after cholecystectomy - a cohort study with 30 years after cholecystectomy - a cohort study with

30 Adami H-O, Meirik O, Gustavsson S, et al. Cholecystectomy and the incidence of breast cancer: a cohort study. Br f Cancer 1984; 49: 235-9.

31 Eriksson SG, Lindströ CG. Lack of relationship between cholecystectomy and colorectal cancer. A case-control study in a defined population. Scand $\mathcal{F}$ Gastroenterol 1984; 19: 977-82.

32 Wysowski DK, Goldberg EL, Comstock GW, et al. A study of a possible association between breast cancer and gallbladder disease. Am $\mathcal{f}$ Epidemiol 1986; 123: $532-43$. 